CLINICAL CASE

\title{
RIGHT TRANSPHRENIC APPROACH OF A LEFT HEPATIC LOBE HYDATID CYST ASSOCIATED WITH RIGHT PULMONARY HYDATID CYST - CASE REPORT
}

\author{
M.I. Popa ${ }^{1}$, Mădălina Buzatu ${ }^{2}$, S. Râmboiu ${ }^{3}$, Monalisa Enache ${ }^{4}$, Serenada Bălă ${ }^{5}$, Camelia \\ Demetrian $^{6}$, S. Voicescu ${ }^{1}$, A.A. Bozgan ${ }^{1}$, A. Demetrian ${ }^{2}$ \\ ${ }^{1}$ University of Medicine and Pharmacy of Craiova, Romania \\ ${ }^{2}$ Thoracic Surgery Clinic - University of Medicine and Pharmacy of Craiova, Romania \\ ${ }^{3}$ Surgery I Clinic - University of Medicine and Pharmacy of Craiova, Romania \\ ${ }^{4}$ Anesthesiology and Intensive Care Clinic - University of Medicine and Pharmacy of Craiova, Romania \\ ${ }^{5}$ Pathology Department- Emergency Departmental Hospital of Craiova, Romania \\ ${ }^{6}$ Pneumology Clinic - University of Medicine and Pharmacy of Craiova, Romania \\ Corresponding author: Popa Mihail Ioan \\ Phone no. 0040740835466 \\ E-mail: popa.mihailioan@yahoo.com
}

\begin{abstract}
The hydatid cyst with double location (lung and liver) is a challenge for the thoraco-abdominal border surgery mainly due to the difficulty of choosing the approach (thoracotomy and laparotomy versus thoracotomy and phrenotomy). We present a case of hydatid cyst with dual location (right lung and left hepatic lobe) resolved by right thoracotomy and right transphrenic approach.
\end{abstract}

Keywords: hydatid cyst, double location, transphrenic approach

\section{Introduction}

The hydatid cyst with double location, pulmonary and hepatic, represents a challenge for choosing the optimal approach, especially when the aim is to minimize the surgical stress by solving simultaneously both locations $[1,2]$. An additional difficulty occurs when the two locations (pulmonary and hepatic) are located contralaterally [3]. The transphrenic right approach of the hepatic hydatid cyst of the left lobe is feasible despite the apparently extremely long path and indirect approach.

\section{Material and methods}

We present the case of a 17-year-old young man, with significant obesity, hospitalized for intense dyspnea and persisting febrile syndrome. The CT scan of the thorax and the abdomen (Figure 1) revealed a right pulmonary giant hydatid cyst, partially evacuated, occupying almost entirely the right lung, with mass effect on the mediastinum. Simultaneously, the patient had a large hydatid cyst $(15 / 12 \mathrm{~cm})$, viable, located in the left lobe of the liver. 


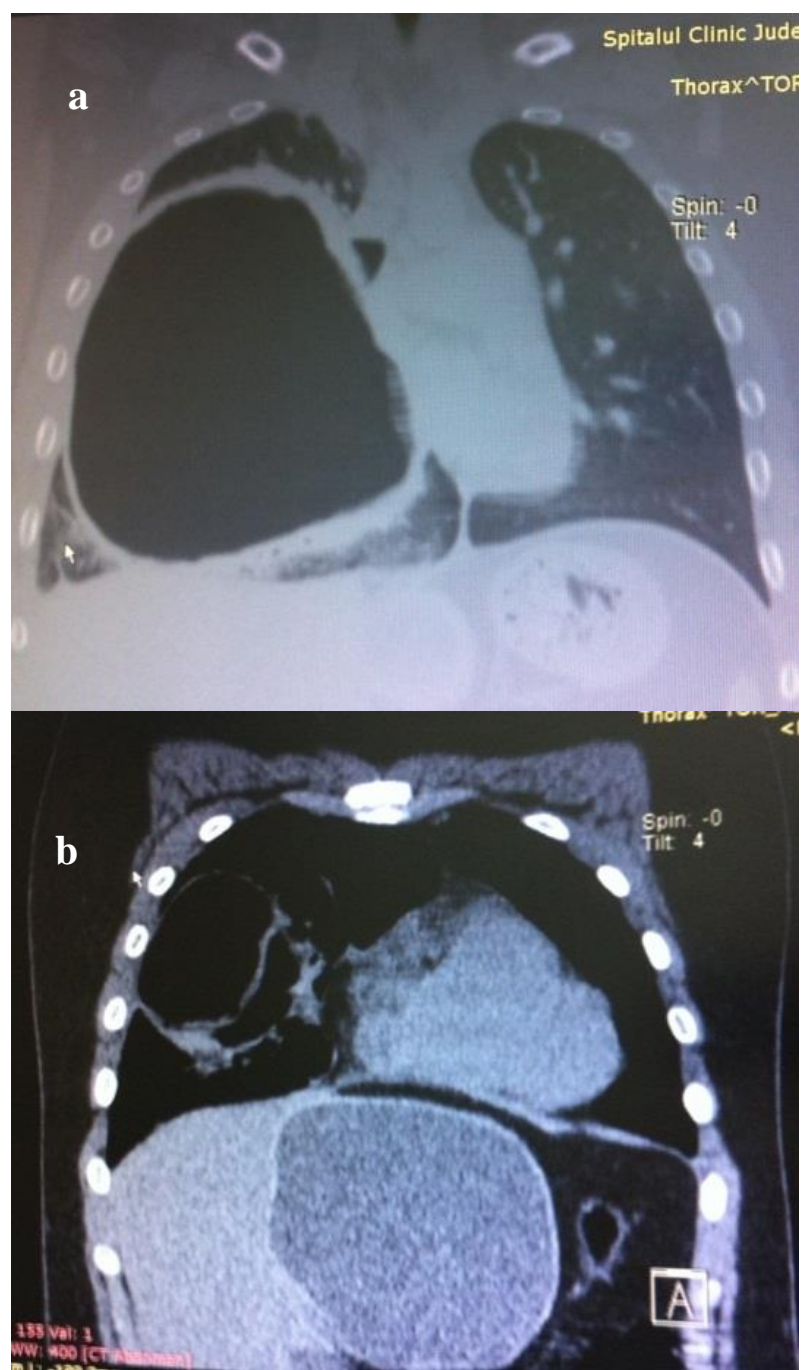

Figure 1 - Preoperative CT scan of the chest and the abdomen

Taking into consideration the biological status of the patient (sepsis, significant dyspnea), the obesity and the benefits of simultaneous solving both locations, we chose to use the right anterolateral thoracotomy followed by right phrenotomy.

\section{Results}

Through the right anterolateral thoracotomy we could evacuate the right lung hydatid cyst (partially evacuated and infected) and performed a partial pericystectomy, the suture of the existing bronchial fistulae, and the clothing of the remaining cavity by purse-string sutures (Dor procedure). After resolving the pulmonary hydatid cyst we performed a $4 \mathrm{~cm}$ long anteromedial phrenotomy sparing the phrenic nerve branches (Figure 2) which allowed as to spot the viable hydatid cyst from the left hepatic lobe of the liver after a minimum traction.

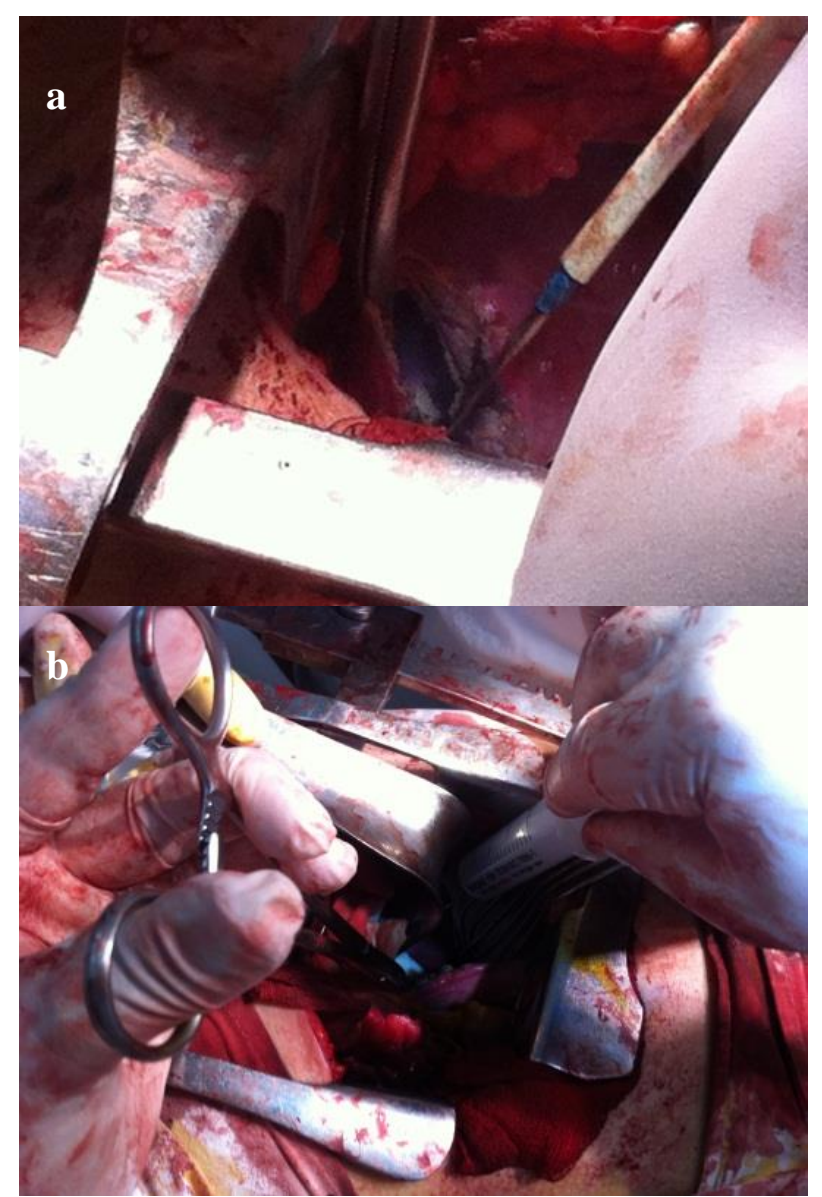

Figure 2 - Right phrenotomy and the puncture of the left hepatic lobe hydatid cyst

Although there is a general perception that the approach of the hydatid cysts of the left hepatic lobe through a right phrenotomy is difficult or impossible, we could puncture it, inactivate and evacuate the cyst and treat the remaining cavity safely (Figure 3), with a satisfying surgical comfort. No biliary fistulae have been found.

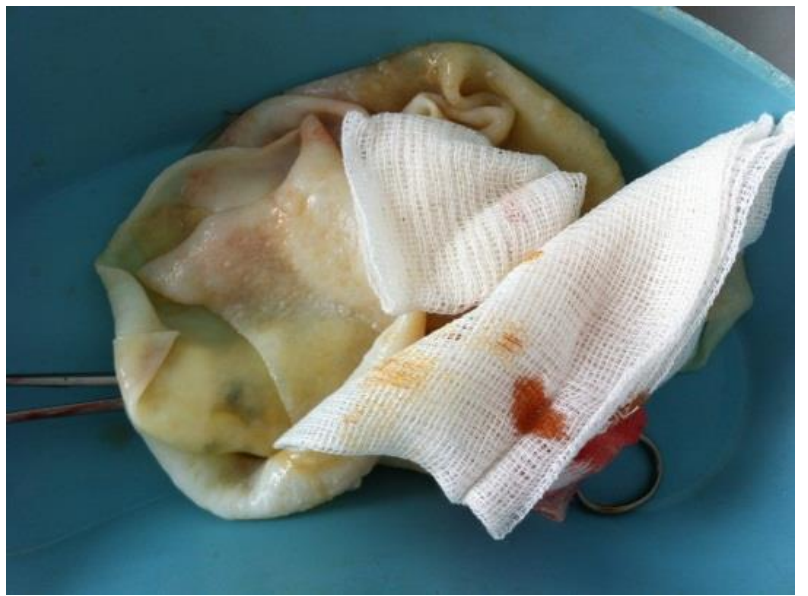

Figure 3 - The proliger membrane evacuated 


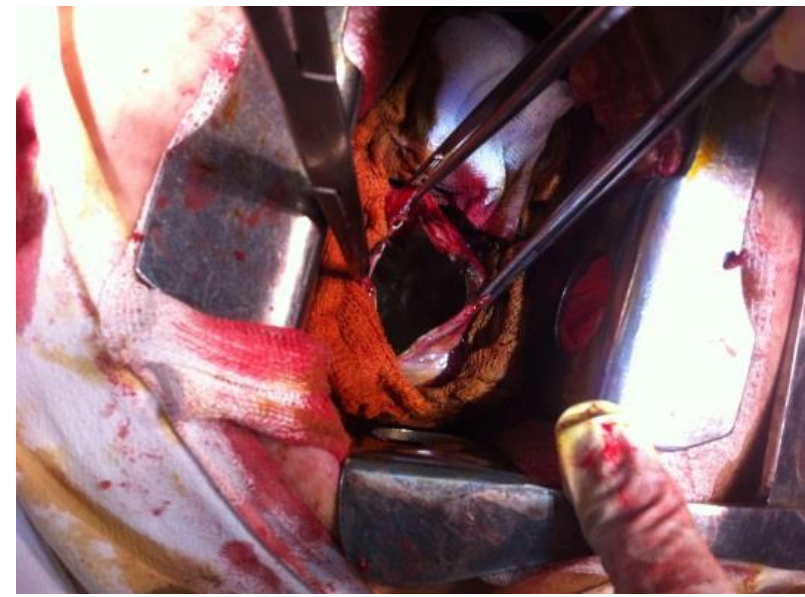

Figure 4 - The remaining cavity of the left hepatic lobe

The draining of the residual cavity of the left hepatic lobe was performed on a path as directly as possible exteriorized in the right subcostal region and an additional suprahepatic drainage was exteriorized in the same manner.

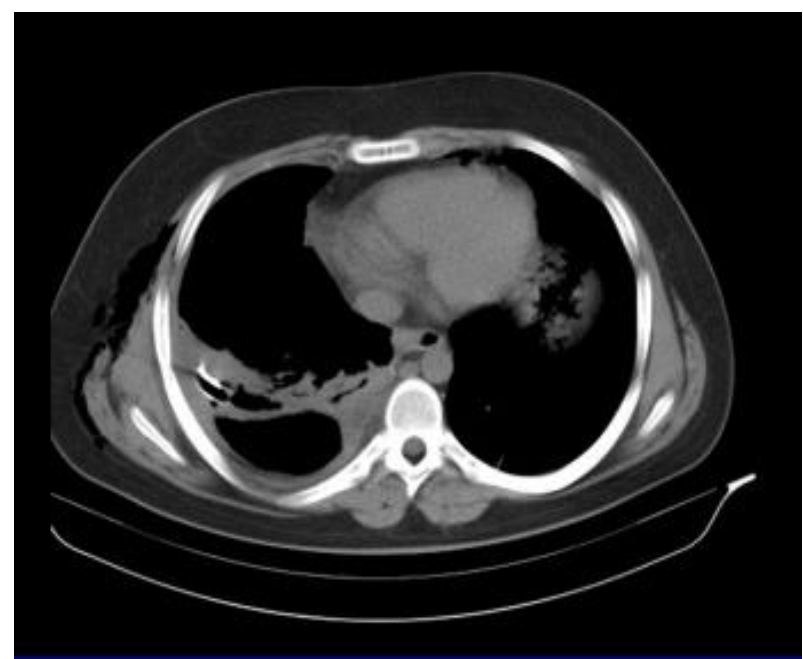

Figure 5 - The CT scan of the thorax after surgery

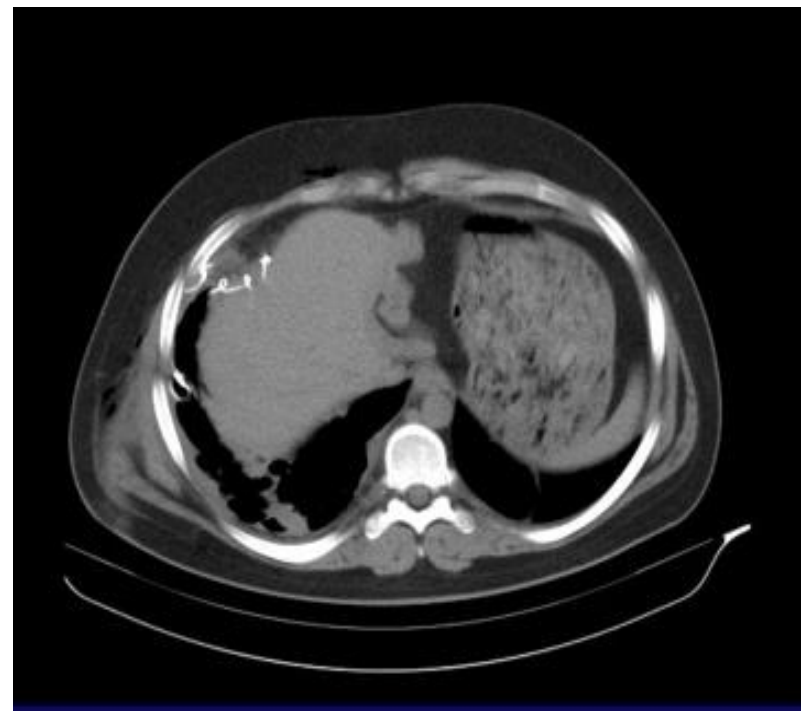

Figure 6 - The CT scan of the abdomen after surgery
The phrenotomy was closed with a double running suture and the double drainage of the right pleural cavity completed the intervention. The postoperative outcome was long but favorable, the patient being discharged 25 days after surgery.

The CT scan of the thorax and the abdomen before discharge (Figure 5,6) revealed satisfactory expansion of the right lung, and the almost total suppression of the left hepatic lobe cavity.

The patient received a parasiticide treatment with Albendazol for 5 months after surgery. The radiological pulmonary control after 5 months showed complete expansion of the right lung (Figure 7).

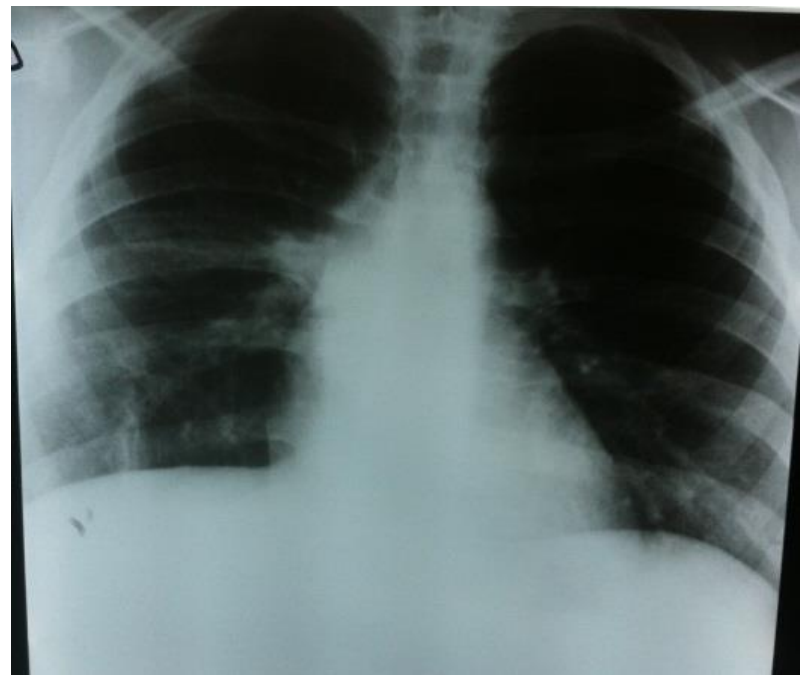

Figure 7 - Chest X-Ray 5 months after operation

\section{Discussions}

Plurivisceral Echinococcosis ( hydatid cyst with multiple locations ) is a broad pathology with various locations requiring multiple approaches to solve it by simultaneous or seriate operations [4].

In the dual locations (lung and liver) the transphrenic approach can be used for the hepatic cyst, thus avoiding a second skin incision (laparotomy).

The advantages of the transphrenic approach in the double locations of hydatid cysts includes:

- One operation, one anesthesia, one incision;

- The easiness of preparation and isolation of the suprahepatic operative field;

- The direct view on the hepatic cyst; 
- The easiness of the complete evacuation of the cyst cavity;

- Simplicity of the drainage of the cavity;

- The minimum risk of contamination of the abdominal cavity.

As we have done, in this particular situation is necessary to resolve first the lung hydatid cyst to avoid contamination of the bronchial tree before the transphrenic approach can be used to solve the hepatic hydatid cyst [5].

\section{Conclusions}

The transphrenic approach of the right hepatic hydatid cysts of the left lobe in dual locations (right lung and the left lobe of the liver), is feasible and safe, allowing to resolve simultaneously both locations and to avoide the laparotomy.

\section{References}

[1]Iselin M, Duban R, Dubat Ch, Duranteau M: Traité de technique chirurgicale, tom IV, Masson et C-ie éditeurs, 1995: 165-205.

[2]Oancea T: Aspecte ale chirurgiei de graniță toracoabdominală, Editura Militară București, 1983: 142-147.

[3]Grozavu C, Parvu A, Demetrian A: Tratamentul medical şi miniinvaziv în echinococoza pluriviscerală" - Revista de Medicină Militară, nr. 1/2007: 41-49.

[4]Grozavu C. Echinococoza pluriviscerală. Chirurgia localizărilor toracoabdominale. București: Editura Universitară Carol Davila, 2008

[5]Kurul IC, Topcu S. One-stage operation for hydatid disease of lung and liver: Principles of treatment. J. Thorac. Cardiovasc. Surg. 2001; 124: 1212-1215. 